\title{
A influência da origem social na probabilidade de concluir os diferentes cursos de ensino superior
}

\author{
Márcia Knop* \\ Ana Cristina Murta Collares**
}

Resumo: O artigo analisa a influência da escolaridade do pai e da renda familiar nas chances de conclusão do ensino superior no Brasil, considerando as diferenças no retorno econômico dos cursos de graduação. Para realizar a análise, utilizamos microdados do Exame Nacional de Desempenho de Estudantes (Enade) e calculamos modelos logísticos. Os resultados principais mostram que, no geral, ter pais com escolaridade mais alta aumenta as oportunidades de conclusão dos cursos. No entanto, no setor público, a escolaridade do pai não tem efeito sobre a probabilidade de concluir o ensino superior. Além disso, a escolaridade do pai exerce maior influência nas chances de conclusão dos cursos de alto retorno econômico. A renda familiar aumenta as probabilidades de conclusão do curso, tanto no setor público como no setor privado da educação. Também encontramos efeitos similares para a renda familiar, independente do retorno econômico dos cursos.

Palavras-chave: Ensino superior. Origem social. Estratificação horizontal.

\section{The influence of social origin on the probability of obtaining a college degree}

Abstract: The article analyzes the impact of parental schooling and family income on students' chances of obtaining a college degree, considering variation in the economic return of undergraduate degrees. We rely on data from National Student Performance Exam (Enade) to estimate logistic regression models. The results show that, in general, students with more educated parents have a greater likelihood of obtaining a degree. However, in public institutions, parental schooling has no effect on the odds of finishing tertiary education. Furthermore, parents' schooling exerts greater influence on the odds of conclusion of those degrees providing greater economic rewards in the job market. Family income increases students' chances of obtaining a degree in both private and public institutions. Also, we find that the effect of family income is the same, regardless of the economic returns of students' degree.

Key words: Higher education. Social background. Horizontal stratification.

\author{
* Márcia Knop é \\ doutoranda em \\ sociologia no \\ Departamento \\ de Sociologia da \\ Universidade de \\ Brasília (UnB), \\ Brasília (DF), Brasil. \\ Orcid: 0000-0001- \\ 9581-1073. \\ <marciaknop@gmail. \\ com>.
** Ana Cristina Murta Collares é doutora em sociologia e professora adjunta do Departamento de Sociologia da Universidade de Brasília (UnB), Brasília (DF), Brasil. Orcid: 0000-0002- 7326-4491. <anacollares@unb. $b r>$.




\section{Introdução}

○

perfil dos concluintes no ensino superior brasileiro tem mudado ao longo dos últimos anos, como mostram diversos estudos (Beltrão et alii, 2016; Ristoff, 2014). De modo geral, observamos concluintes com perfis socioeconômicos menos elitizados nesse nível de ensino, embora exista uma variação bastante considerável desses perfis entre as diferentes áreas de estudo. A redução da frequência de perfis elitizados deve ser interpretada com cautela. Mostrar essas mudanças não significa dizer que a origem familiar deixou de ter influência nas chances de ingresso ou de conclusão dos diferentes cursos ofertados. Essa relação ainda permanece e apresenta diferentes intensidades, de acordo com o tipo de instituição, a área de estudo etc. Contudo, ela pode ter se tornado menos influente em determinar os destinos sociais dos indivíduos.

Estudos sobre a influência da educação, na relação entre origens e destinos sociais dos indivíduos, costumam justificar a permanência dessa relação origem-trajetória ou origem-destino a partir de duas teorias combinadas - a teoria da Desigualdade Mantida ao Máximo (Maxymally Maintained Inequality) e a teoria da Desigualdade Efetivamente Mantida (Effectively Maintained Inequality) (Silva, 2003; Carvalhaes e Ribeiro, 2019; Beltrão et alii, 2016; Ribeiro, 2011; Ayalon et alii, 2008). A teoria da Desigualdade Mantida ao Máximo (MMI) foi desenvolvida por Raftery e Hout (1993) ao realizarem um estudo sobre a ampliação da educação superior na Irlanda. Posteriormente, outros estudos chegaram a conclusões semelhantes para outros países (Bossfield \& Shavit, 1993). De forma resumida, os autores argumentam que a expansão de um nível de ensino somente chegará às classes menos favorecidas quando as classes de maior renda já o tiverem saturado, ou seja, já tiverem obtido todas as vagas que desejavam. Assim, a desigualdade de acesso nesse nível educacional iria se reduzir, porém a disputa por uma vaga seria transferida para o nível seguinte.

Complementar à teoria anterior, Lucas (2001) propôs a teoria da Desigualdade Efetivamente Mantida (EMI). Segundo o autor, mesmo quando um nível de ensino é expandido ou universalizado, as desigualdades tendem a se manter por meio de subdivisões criadas dentro de cada nível de ensino, selecionando indivíduos de diferentes origens sociais para instituições/cursos com qualidades e prestígios distintos. Essa teoria está relacionada com a dimensão horizontal da estratificação, uma vez que leva em consideração as diferenças qualitativas das trajetórias escolares. Essa teoria também foi ratificada por outros estudos (AyaIon \& Yogev, 2005). 
Nessa mesma linha, estudos recentes vêm discutindo que a influência - seja vertical, seja horizontal - das origens sociais nas oportunidades de acesso e graduação no ensino superior varia por áreas de estudo (Werfhorst, 2001; Bertolin et alii, 2019, dentre outros), indicando que algumas áreas ou alguns tipos de instituições podem ser mais seletivos do que outros. Essa diferenciação entre as chances de acesso e graduação por área de estudo variam contextualmente, tendo sido encontrados resultados diversos em diferentes países. Por exemplo lannelli et alii (2018) estudaram o papel das áreas de conhecimento e do tipo institucional como mecanismos de manutenção da estratificação social no ensino superior escocês, encontrando que, quando as áreas de conhecimento são classificadas de acordo com o retorno no mercado de trabalho, elas não atuam como mecanismos de reprodução social. Já na Itália, Triventti et alii (2017) mostram que indivíduos de origem socioeconômica menos privilegiada tendem a concluir cursos de menor prestígio e de retorno econômico mais incerto no mercado de trabalho italiano, como os cursos da área de ciências sociais. Já indivíduos de origem socioeconômica mais privilegiada graduam-se nas áreas de conhecimento que proporcionam maiores retornos econômicos. Em ambos os exemplos, o desempenho acadêmico dos estudantes foi utilizado como variável de controle da relação origem social $\leftrightarrow$ área cursada $\leftrightarrow$ chances de conclusão.

Em síntese: os mecanismos de seleção para instituições de prestígio e áreas de maior retorno financeiro no mercado de trabalho, em cada país, variam e não necessariamente estão positivamente correlacionados à origem socioeconômica dos estudantes.

Vários estudos centrados especificamente no Brasil (Fernandes, 2004; Mont'alvão, 2011; Carvalhaes \& Ribeiro, 2019) verificaram a aplicabilidade tanto da teoria da MMI quanto da EMI no contexto nacional, mostrando um declínio da influência das origens familiares em seguida à expansão das séries iniciais, com uma intensificação ou a não redução do efeito das origens sociais nas últimas transições do sistema de ensino (Silva, 2003; Rios-Neto \& Guimarães, 2010). Porém, após alcançado o nível superior de ensino, continuariam esses fatores a exercer sua influência nas chances de conclusão? Com que intensidade? Seria essa influência diferente por área de estudo?

O presente estudo se propõe discutir estas questões, investigando se a origem familiar, tão importante para o acesso ao ensino superior no Brasil, continua sendo um fator significativo que influencia as chances de conclusão dos graduandos, e se essa influência se exerce de maneira distinta nas diferentes áreas de estudo. Tomamos por pressuposto que a influência das origens sociais no acesso ao en- 
sino superior se dá de maneira diferenciada por área de estudo, e também por tipo de instituição (por exemplo universidade, faculdade etc.) (e.g. Collares, 2010; Barbosa, 2015) e desse modo seleciona grupos de alunos com origens familiares diferentes em cada área. A seletividade de cada curso afetaria ainda não apenas quem entra em cada curso, mas a resiliência dos alunos de diferentes origens sociais dentro deste, ou seja, suas chances de conclusão (Prates \& Collares, 2014).

Com esse intuito, fizemos uma comparação entre ingressantes e concluintes do ensino superior a fim de demonstrar a importância da origem social dos estudantes na conclusão dos cursos, e investigar se esse impacto da origem social varia por instituição e por área de estudo ou graduação. Foram testadas cinco hipóteses, apresentadas nas próximas seções juntamente com os dados e a metodologia empregados. Para apresentar o comportamento dessas variáveis entre as diferentes graduações, classificamos os cursos de acordo com o retorno econômico estimado no mercado de trabalho (alto, médio e baixo retorno), e testamos os efeitos da origem social por impacto econômico. O artigo se divide em cinco seções: esta introdução, uma seção onde situamos as questões de pesquisa no contexto brasileiro e apresentamos as hipóteses; uma seção onde são expostos os dados e a metodologia de análise, e uma seção de apresentação e discussão dos resultados. Por fim, na última sessão apresentamos algumas considerações finais.

\section{Contextualização do problema e hipóteses de trabalho}

Em regra, as variáveis utilizadas para medir a origem familiar em estudos sobre estratificação educacional no Brasil costumam ser renda familiar e escolaridade dos pais. Embora essas duas variáveis estejam muito relacionadas, nem sempre elas apresentam efeitos similares para explicar determinado resultado na educação. Como exemplo, pode-se observar os estudos sobre transições educacionais (passagem de um nível de ensino para outro) no Brasil. Hasenbalg e Silva (2003), em estudo sobre esse tema, mostraram um efeito decrescente da educação do pai ao longo das transições educacionais, enquanto que a renda familiar não apresentava impacto nos três anos iniciais da educação compulsória, mas apresentava efeito crescente nos anos posteriores.

No caso do ensino superior brasileiro, a literatura reporta diferenças entre os setores público e privado em relação às variáveis citadas. Prates e Collares (2014), por exemplo, mostraram que o impacto da renda é importante tanto para o setor público como para o privado, mas é ainda mais elevado para este último. A explicação geralmente dada para isso é o fato de as instituições do setor privado 
cobrarem mensalidades, enquanto o setor público não, é gratuito. Já o efeito da escolaridade dos pais se mostrou mais sensível no setor público do que no privado. Esse resultado costuma ser justificado a partir da ideia de que as instituições do setor público são mais seletivas em termos acadêmicos, de modo que estudantes com pais mais escolarizados propiciariam melhores condições para o desenvolvimento de habilidades cognitivas necessárias para a competição por uma vaga na educação superior. No entanto, é preciso investigar se esses dois fatores - renda familiar e escolaridade do pai -, que atuam na seleção dos estudantes no momento do acesso ao ensino superior, continuam atuando no decorrer do curso e influenciando as chances de conclusão da graduação.

Com base nessas questões, nossa primeira hipótese relaciona-se com a resiliência de determinados estudantes. Prates e Collares (2014), comparando dados da Pesquisa Nacional por Amostra de Domicílios (Pnad) e do Provão (2003), encontraram indícios de que os estudantes que abandonam o ensino superior em maior quantidade, na rede pública ou privada, seriam aqueles cujos pais possuem educação secundária, e não aqueles cujos pais possuem nenhuma ou baixa escolaridade. Conforme os autores, tal achado é compatível com estudos que afirmam ser a escolaridade dos pais um fator muito importante para a entrada no ensino superior. Dessa forma, aqueles estudantes cujos pais possuem baixa ou nenhuma escolaridade, mas ainda assim conseguem entrar na educação superior, seriam um grupo selecionado e resiliente, com maiores chances de concluir o curso do que aqueles cujos pais são mais escolarizados. Sendo assim, a primeira hipótese a ser testada neste artigo é a seguinte:

(1) Estudantes cujos pais possuem baixa escolaridade apresentam maior resiliência, ou seja, maior probabilidade de permanecerem e concluírem o curso uma vez ultrapassada a barreira da entrada, em relação aos estudantes cujos pais possuem escolaridade mais elevada.

Ainda referindo-nos à hipótese anterior, os mesmos autores também encontraram que o efeito da escolaridade dos pais nas chances de acesso ao ensino superior, embora seja importante para ambos os setores, foi maior no setor público do que no setor privado. Sendo assim, poderíamos especular se os estudantes com pais de baixa escolaridade que, ainda assim, conseguem entrar no ensino superior público, academicamente mais competitivo, seriam mais resilientes do que aqueles do ensino superior privado. Sendo assim, uma hipótese derivada da primeira seria:

(1.1) Estudantes do setor público com pais de baixa escolaridade são mais resilientes do que estudantes do setor privado com pais de baixa escolaridade. 
1. Essas descobertas diferem entre contextos institucionais diferentes (por exemplo, as descobertas de lanelli, Gamoran \& Paterson (2018) para a Escócia).
Sobre a escolaridade do pai, temos ainda que considerar outros fatores. De acordo com a literatura (Arum, Gamoran \& Shavit, 2007; Gerber \& Sheung, 2008; Carvalhaes \& Ribeiro, 2019), a expansão do ensino superior reserva as melhores oportunidades de formação para aqueles com origens sociais mais privilegiadas. Beltrão et alii (2016) concluíram que a inclusão de estudantes no ensino superior brasileiro foi enviesada, pois estudantes de origem familiar mais baixa concluem cursos de menor demanda e/ou em instituições de menor prestígio. Por consequência, cursos de maior retorno econômico tendem a ter concluintes de perfil socioeconômico mais privilegiado, o que implica em estudantes com pais mais escolarizados ${ }^{1}$. Soma-se a isso a falta de perspectiva no mercado de trabalho para algumas carreiras, o que representa um fator que influencia a desistência do curso, como é o caso das licenciaturas, consideradas cursos de baixo retorno econômico (Cardoso, 2008; Carvalho \& Oliveira, 2014; Massi \& Villani, 2015). Se for assim, cabe testar a seguinte hipótese:

(2) Estudantes cujos pais possuem baixa escolaridade concluem com maior frequência cursos considerados como de menor retorno econômico.

Em relação à outra variável de origem social a ser aqui discutida - a renda familiar -, estudos anteriores têm apontado que, tanto no setor público como no setor privado as médias das rendas familiares dos universitários são semelhantes. No entanto, parece haver mais estudantes de renda baixa no setor público do que no setor privado (Corbucci, 2007). Essa mesma constatação foi feita por Prates e Collares (2014), a partir de amostras tanto da Pnad como do Provão de 2003, apontando que há uma maior concentração de estudantes das faixas de renda familiar mais baixas no setor público, enquanto os estudantes das faixas de renda familiar mais elevadas concentram-se preferencialmente no setor privado.

Diversos estudos demonstram a permanência da influência da renda familiar no acesso à educação superior, a despeito do decréscimo dessa influência nos primeiros anos do ensino fundamental (Torche \& Costa-Ribeiro, 2012; Rios-Neto \& Rangel, 2010, dentre outros) ${ }^{2}$.

Andrade (2012), a parir dos dados da Pnad, mostra que, em 2009, no 1o quintil de renda familiar (o mais baixo) apenas $3 \%$ dos jovens em idade universitária (18 a 24 anos) tiveram acesso ao ensino superior. Já no 5 quintil de renda familiar (o mais elevado), esse percentual foi de $60 \%$. É verdade que esses dados estão datados, principalmente ao se considerar a expansão do crédito universitário que se manteve até 2014 e que pode ter alterado esses valores em alguma medida, 
diminuindo a desigualdade de acesso ao ensino superior entre os quintis de renda. De todo modo, dificilmente essa provável redução na desigualdade de acesso conseguiria reverter o quadro, como sugere a análise de Salata (2018) com dados até 2015. Prates e Collares (2014), por meio de regressão logística multinomial com dados das Pnad's (1982, 2001 a 2003, e 2004 a 2006), mostraram a influência da renda familiar nas chances de matrícula na educação superior. Para ambos os setores, o impacto da renda familiar é elevado. No entanto, para o setor privado, o impacto era ainda mais alto - para cada unidade de aumento na escala logarítmica de renda familiar, as chances de estar matriculado no setor privado aumentavam 2,8 vezes, enquanto no setor público esse valor era de 1,9 . Se olharmos a redução das desigualdades de acesso ensino superior por classe de origem, Salata (2018) indica que, apesar de o acesso permanecer bastante desigual, houve redução na desigualdade de acesso por classe de origem entre 2005 e 2015.

Em suma, a literatura tem apontado que a renda familiar exerce influência considerável nas chances de acessar o ensino superior, e essa influência tende a ser maior no setor privado. É de se esperar que essas diferenças atuem sobre as chances de conclusão dos cursos. A própria literatura sobre evasão parece corroborar essa dedução, já que a inadimplência aparece como um dos fatores que aumentam as chances de desistência do curso nas instituições privadas (Gaioso, 2005; Andriola et alii, 2006; Andrade et alii, 2007; Lobo, 2012; Silva, 2013). Isso nos leva à terceira e à quarta hipóteses de investigação deste estudo:

(3) Estudantes provenientes de famílias de renda mais baixa têm menor probabilidade de concluir os cursos quando comparados com estudantes de famílias de renda mais elevada;

(4) A probabilidade de estudantes provenientes de famílias de renda mais baixa concluírem os cursos é maior no setor público do que no setor privado.

Além disso, cabe também considerar aqui a influência do retorno econômico dos cursos. Ao que parece, os cursos de alto retorno econômico exigem mais dedicação dos alunos, o que significa mais horas disponíveis de estudo, portanto ter uma renda familiar mais elevada, sem necessidade de trabalhar para custear os próprios estudos é um importante diferencial para se manter nesses cursos e concluí-los. No entanto, essa disponibilidade de tempo e de recursos parece ir na contramão do perfil do "novo aluno" do ensino superior, apontado por alguns estudos brasileiros: são mais velhos, frequentam cursos noturnos, geralmente de baixa seletividade, em instituições privadas, utilizam parte do tempo para garantir sua subsistência, muitos deles constituem a primeira geração de longa escolaridade 
de suas famílias, não dispõem de tempo e de condições apropriadas para estudar nem para se dedicar às atividades acadêmicas extraclasse (Carvalho, 2007; Nunes, 2007; Brito et alii, 2008; Almeida et alii, 2012).

Sendo assim, é possível que, para manter-se no ensino superior, parte dos estudantes tenha de conciliar o estudo com uma atividade profissional remunerada. Um levantamento descritivo simples da base de dados utilizada para este artigo mostrou a seguinte composição de estudantes que trabalham por tipo de curso (retorno econômico dos cursos): entre os estudantes de cursos de médio e baixo retorno, 68,2\% declararam trabalhar, já nos cursos de alto retorno econômico, esse percentual é de $49,9 \%$. De forma complementar, entre todos os estudantes que declararam trabalhar, cerca de $76 \%$ estão em cursos de baixo e médio retorno econômico, e apenas cerca de $24 \%$ estão nos cursos de alto retorno econômico. Portanto, ao se considerar os dados descritivos acima e a literatura, a quinta hipótese a ser testada é a seguinte:

(5) Estudantes de renda familiar mais elevada têm maior probabilidade de concluir os cursos de alto retorno econômico do que estudantes de renda familiar mais baixa.

\section{Dados e metodologia}

2. Para a análise dos dados, foi utilizado o software R. Utilizamos o pacote Zelig do $R$ tanto para o cálculo dos modelos logísticos quanto para calcular os efeitos marginais.
Nesta análise, utilizamos os microdados do Questionário do Estudante do Exame Nacional de Desempenho do Estudante (Enade), disponibilizados no site do Instituto Nacional de Estudos e Pesquisas Educacionais Anísio Teixeira (Inep)². O Enade é uma avaliação trienal e os cursos são divididos em três grandes grupos que se revezam ano a ano na avaliação. Assim, a cada três anos, um mesmo grupo de cursos é reavaliado. Para este artigo, era necessário comparar ingressantes e concluintes dos mesmos cursos. Sendo assim, para os ingressantes, utilizamos os dados do triênio mais recente em que os ingressantes ainda eram avaliados: 2008, 2009 e 2010 (a partir de 2011 o Enade passou a ser aplicado apenas para concluintes). E optamos por utilizar os dados dos concluintes considerando um lapso de três anos após a entrada no curso, por isso selecionamos o triênio 2011, 2012 e 2013.

O Enade considera "ingressante" aquele que tenha iniciado o curso no ano de aplicação do exame, devidamente matriculado, e que tenha no máximo 25\% da carga horária mínima do currículo do curso cumprida até o final das inscrições do Enade daquele ano. O "concluinte" é aquele que tem expectativa de conclusão do curso até meados do ano seguinte ao da aplicação do exame ou que já tenha cumprido $80 \%$ ou mais da carga horária mínima do currículo do curso até o final das inscrições do Enade daquele ano. 
Foram considerados 35 cursos nessa análise, sem fazer distinção entre bacharelado e licenciatura. Não foram incluídos os cursos de tecnólogos, pois a classificação do salário médio dos cursos apresentada por Neri (2005), que utilizamos para este estudo, não inclui esse tipo de graduação. Os cursos aqui analisados foram os seguintes:

i. Anos 2008 (ingressantes) e 2011 (concluintes): arquitetura e urbanismo, biologia, ciência da computação, ciências sociais, engenharias, filosofia, física, geografia, história, letras, matemática, pedagogia e química.

ii. Anos 2009 (ingressantes) e 2012 (concluintes): administração, ciências contábeis, ciências econômicas, comunicação social, design, direito, psicologia, relações internacionais, secretariado executivo e turismo.

iii. Anos 2010 (ingressantes) e 2013 (concluintes): agronomia, biomedicina, enfermagem, farmácia, fisioterapia, fonoaudiologia, medicina veterinária, medicina, nutrição, odontologia, serviço social e zootecnia.

A classificação dos cursos conforme o retorno da educação no mercado de trabalho baseou-se no estudo de Neri (2005). Nesse estudo, entre outras coisas, o autor elaborou um ranking das carreiras por salário médio de cada uma, a partir de microdados do Censo Demográfico de 2000/IBGE. Para o nosso estudo, atribuímos para os 35 cursos os salários médios calculados por Neri (2005) e elencamos os cursos em três grupos - alto, médio e baixo retorno. A seguir reportamos os cursos classificados em cada grupo:

i. Alto retorno: agronomia, arquitetura e urbanismo, ciências econômicas, design, direito, engenharias, medicina, medicina veterinária e odontologia.

ii. Médio retorno: administração, ciência da computação, ciências contábeis, ciências sociais, comunicação social, enfermagem, farmácia, física, matemática, psicologia, química, relações internacionais, secretariado executivo, turismo e zootecnia.

iii. Baixo retorno: biologia, biomedicina, filosofia, fisioterapia, fonoaudiologia, geografia, história, letras, nutrição, pedagogia e serviço social. 
3. A tabela de áreas de conhecimento da Capes está disponível em: $<$ http://www.capes. gov.br/avaliacao/ instrumentosde-apoio/ tabela-de-areasdo-conhecimentoavaliacao>.
Além da classificação por salário médio, também categorizamos os cursos por áreas de conhecimento, tendo como base a divisão por grandes áreas utilizada atualmente pela Capes $^{3}$, embora nossa classificação não seja exatamente igual a essa. As diferenças entre a classificação da Capes e a que adotamos foram as seguintes: fundimos as áreas de humanas e letras em uma única categoria, incorporando os cursos de letras ao grupo das humanas; incluímos o curso de biologia à área da saúde; incorporamos os cursos de arquitetura e urbanismo e design na área das engenharias, por entender que tais cursos estão próximos da engenharia civil; incluímos o curso de relações internacionais na área de ciências sociais aplicadas (na Capes, ele estava no grupo dos cursos multidisciplinares). Dessa forma, os cursos foram assim classificados:

i. Área agrárias: agronomia, medicina veterinária e zootecnia.

ii. Área ciências exatas: ciência da computação, física, matemática e química.

iii. Área humanas e letras: ciências sociais, filosofia, geografia, história, letras, pedagogia e psicologia.

iv. Área ciências sociais aplicadas: administração, ciências contábeis, ciências econômicas, comunicação social, direito, relações internacionais, secretariado executivo, serviço social e turismo.

v. Área engenharias: todas as engenharias, arquitetura e urbanismo e design.

vi. Área saúde: biologia, biomedicina, enfermagem, farmácia, fisioterapia, fonoaudiologia, medicina, nutrição e odontologia.

Como a nossa ideia era comparar ingressantes e concluintes, optamos por analisar modelos de regressão logística que têm como variável resposta o binômio "ser concluinte" (y =1) ou "ser ingressante" ( $y=0)$ do ensino superior. Os modelos empregados seguem a forma geral abaixo:

$\log \left[\frac{\operatorname{Prob}(Y=1)}{\operatorname{Prob}(Y=0)}\right]=B_{0}+B_{1} X_{1}+B_{2} X_{2}+\sum B_{i} X_{i}$

onde:

$Y=1$ indica a probabilidade (log likelihood) de conclusão do ensino superior para alunos que ingressaram nesse nível de ensino, dada a renda familiar e a educação do pai (representando as origens familiares) e uma série de outros controles $\left(X_{i}\right)$; 
$B_{1}$ indica o peso da renda familiar do estudante $\left(X_{1}\right)$ na probabilidade de concluir o ensino superior;

$B_{2}$ indica o peso da escolaridade do pai do estudante $\left(X_{2}\right)$ na probabilidade de concluir o ensino superior;

$B_{i}$ representa o peso dos demais controles do modelo na probabilidade de conclusão, representados pelo vetor $X_{i}$, variando de $i$ a $n$ (sexo, cor/raça, região, área de conhecimento, idade e situação de trabalho).

A variável sexo apresenta as categorias: masculino e feminino. A variável cor/raça foi categorizada da seguinte forma: branca/amarela e negra/indígena. Quanto à escolaridade do pai, são cinco opções: nenhuma; ensino fundamental 1; ensino fundamental 2; ensino médio; ensino superior/pós-graduação. A renda familiar possui quatro categorias: até 3 SM (salários mínimos); entre 3 e 10 SM; entre 10 e 30 SM; acima de 30 SM. A variável região refere-se à região de funcionamento do curso superior em que o estudante encontra-se matriculado: Norte; Nordeste; Centro-Oeste; Sul; Sudeste. A variável área de conhecimento do curso refere-se às seis áreas de conhecimento que apresentamos na seção anterior: agrárias; ciências exatas; humanas e letras; ciências sociais aplicadas; engenharias; saúde. A variável idade foi dividida em seis faixas etárias: até 24 anos; 24-29 anos; 30-34 anos; 35-39 anos; 40-44 anos; mais de 45 anos. A variável trabalha foi transformada numa variável binária - sim ou não. A categoria "sim" inclui qualquer carga horária de trabalho declarada conforme as alternativas de resposta do questionário: trabalho eventualmente; trabalho até 20 horas semanais; trabalho de 21 a 39 horas semanais; trabalho 40 horas semanais ou mais. Não são consideradas como "trabalho" as atividades de estágio, bolsas de pesquisa ou monitoria.

Os modelos de análise foram ajustados para o teste de cada hipótese apresentada na seção anterior, e serão apresentados e discutidos na próxima seção. Para facilidade de interpretação, os resultados são expressos em razões de chance (odds ratios).

\section{Análise e discussão dos resultados}

A Tabela 1 apresenta o modelo completo que utilizamos nesse artigo. Como nosso objetivo é verificar a importância da origem social, nossas variáveis de interesse são renda familiar e escolaridade do pai. As demais variáveis são de controle: sexo, cor/raça, região do curso, trabalha (concilia trabalho e estudo), idade e área de conhecimento do curso. 
TABELA 1

A INFLUÊNCIA DA ESCOLARIDADE DO PAI

E DA RENDA FAMILIAR NAS CHANCES

DE CONCLUSÃO DO ENSINO SUPERIOR

VARIÁVEL RESPOSTA: CONCLUINTE DO ENSINO SUPERIOR

\begin{tabular}{|c|c|c|c|c|}
\hline & Exp.(B) & B & Erro & Sig. \\
\hline (Constante) & 0.76904 & -0.26261 & 0.01064 & $1.53 E-134$ \\
\hline Masculino & 0.84671 & -0.1664 & 0.0042 & 0 \\
\hline Negro/Indígena & 1.01146 & 0.0114 & 0.00432 & 0.008307 \\
\hline Renda 3 a 10 SM & 1.42267 & 0.35253 & 0.00435 & 0 \\
\hline Renda 10 a 30 SM & 1.46351 & 0.38084 & 0.00683 & 0 \\
\hline Renda acima de 30 SM & 1.44504 & 0.36814 & 0.01212 & $1.26 \mathrm{E}-202$ \\
\hline Centro-Oeste & 1.10549 & 0.10029 & 0.00676 & $8.18 \mathrm{E}-50$ \\
\hline Nordeste & 1.08349 & 0.08018 & 0.00552 & $7.69 E-48$ \\
\hline Norte & 1.16211 & 0.15024 & 0.00871 & $9.83 E-67$ \\
\hline Sul & 1.05132 & 0.05004 & 0.00507 & $5.93 E-23$ \\
\hline Escolaridade do pai- EF1 & 1.12872 & 0.12109 & 0.00906 & $9.03 E-41$ \\
\hline Escolaridade do pai- EF2 & 1.05289 & 0.05154 & 0.00992 & $2.07 \mathrm{E}-07$ \\
\hline Escolaridade do pai-EM & 1.22329 & 0.20154 & 0.0094 & $6.17 \mathrm{E}-102$ \\
\hline Escolaridade do pai-ES/PG & 1.47448 & 0.38831 & 0.01002 & 0 \\
\hline Trabalha & 0.97681 & -0.02346 & 0.00436 & $7.34 \mathrm{E}-08$ \\
\hline Idade $25-29$ anos & 3.49455 & 1.2512 & 0.00519 & 0 \\
\hline Idade $30-34$ anos & 3.40216 & 1.22441 & 0.00685 & 0 \\
\hline Idade 35-39 anos & 3.23951 & 1.17542 & 0.00865 & 0 \\
\hline Idade 40-44 anos & 3.35805 & 1.21136 & 0.01077 & 0 \\
\hline Idade 45 ou mais anos & 3.79357 & 1.33331 & 0.01053 & 0 \\
\hline Área saúde & 0.57522 & -0.55301 & 0.0068 & 0 \\
\hline Área exatas & 0.91809 & -0.08546 & 0.00974 & $1.79 \mathrm{E}-18$ \\
\hline Área engenharias & 0.66517 & -0.40771 & 0.00854 & 0 \\
\hline Área sociais aplicadas & 0.70926 & -0.34353 & 0.00563 & 0 \\
\hline Área agrárias & 0.65722 & -0.41973 & 0.01279 & $2.79 E-236$ \\
\hline
\end{tabular}

A última coluna da tabela - Significância (Sig.) - mostra que todos os resultados são estatisticamente significativos $(p<0,05)$, o que não surpreende, dado o elevado número de casos na amostra. A primeira coluna - Exp.(B) - mostra a razão de chance entre cada variável e a categoria de referência, e a coluna $B$ expressa os resultados em sua forma logarítmica. Quanto às nossas variáveis de interesse, a categoria de referência da variável renda familiar é "até 3 salários mínimos". 0 
modelo mostra que uma renda superior a 3 salários mínimos aumenta as chances de conclusão do ensino superior, e as duas faixas de renda mais altas apresentam chances ainda maiores. Esse resultado já era esperado, considerando a importância da renda para o ensino superior apontada pela literatura da área e já apresentada aqui.

Em relação à escolaridade do pai, a categoria de referência é "nenhuma escolaridade". O modelo sugere que ter alguma escolaridade, qualquer que seja, aumenta as chances de conclusão do ensino superior. Assim como acontece com a renda, os dois níveis mais altos de escolaridade do pai também apresentam chances maiores de concluir o curso. Uma vez que a literatura da área mostra a importância da escolaridade do pai nas chances de acesso ao ensino superior era possível que esse efeito também fosse importante para a conclusão dos cursos. No entanto, conforme já citado aqui, também é verdade que alguns estudos, utilizando bases de dados diferentes da nossa, sugerem que os estudantes que abandonam o ensino superior em maior quantidade são aqueles cujos pais possuem educação secundária, e não aqueles cujos pais possuem nenhuma ou baixa escolaridade. Por exemplo, em Prates e Collares (2014), estudantes com pais de baixa escolaridade se formavam em maiores proporções, com relação à proporção de ingressantes, do que os estudantes filhos de pais com escolaridade mais elevada. Nesse caso, apenas as proporções de ingresso/graduação de alunos foram calculadas, com base em características como renda familiar e escolaridade dos pais. Nosso modelo compara alunos semelhantes com relação aos diversos controles. Em um modelo (não mostrado aqui) apenas com renda e escolaridade, sem controles, alunos com pais de escolaridade mais baixa também apresentam maior resiliência, ou seja, maiores possibilidades de graduação. Esse efeito é ligeiramente maior no setor privado do que no setor público de educação.

Em relação às variáveis de controle, vale destacar que negros e indígenas parecem ter uma pequena vantagem sobre brancos e amarelos com "tudo o mais constante", de cerca de 11\%, nas chances de concluir os cursos. A resiliência dos negros (pretos e pardos), uma vez matriculados no ensino superior, já foi registrada pela literatura. Prates e Collares (2014) mostraram, por exemplo, que a proporção de pretos e pardos entre os formandos é mais alta do que a proporção de pretos e pardos entre os que se matriculam. Os demais resultados são os já encontrados na literatura: as mulheres se graduam em maiores proporções que os homens; quando comparadas à Região Sudeste, todas as demais regiões apresentam mais chances de conclusão para alunos semelhantes; estudantes que conciliam os estudos com uma atividade profissional parecem ter uma pequena desvantagem em relação aos que não trabalham - algo em torno de 2,3\% de chances a menos 


\section{Um dos}

motivos para esse

resultado pode

ser a seletividade

acadêmica de cada

área. Nesse sentido,

cursos das áreas

de engenharias

e de exatas, por

exemplo, costumam

apresentar altas

taxas de reprovação

em suas matérias; a

disciplina de Cálculo

1 é um exemplo

clássico retratado

pela literatura

(Garzella, 2013), retardando o tempo de conclusão do curso ou culminando em sua desistência. Desse modo, dados os controles e o fato de que todos os estudantes na amostra já estão no sistema, não surpreende que letras e humanidades tenham maior taxa de conclusão. Vale acrescentar também que apesar de os cursos de humanas serem menos competitivos na entrada e de se encontrarem em maior quantidade no setor privado, há dois cursos classificados no nosso grupo de "humanas e letras", pedagogia e psicologia, que estão entre os cursos com maior número de concluintes, segundo - Censo da Educação Superior/2016.

de concluir o curso. Quanto à idade, a categoria de referência do nosso modelo é "até 24 anos". Qualquer faixa etária superior a essa apresenta vantagem nas chances de conclusão do curso, o que é esperado, especialmente em um modelo que controla outras diferenças entre alunos mais jovens e mais velhos, uma vez que a idade média atual dos estudantes do ensino superior brasileiro é 26 anos, conforme dados do Censo da Educação Superior/2017. Sobre as áreas de conhecimento dos cursos, comparada com a área de humanas e letras (categoria de referência), todas as demais áreas apresentam desvantagem nas chances de concluir o curso ${ }^{4}$.

\section{TABELA 2}

A INFLUÊNCIA DA ESCOLARIDADE DO PAI

E DA RENDA FAMILIAR NAS CHANCES DE CONCLUSÃO

DO ENSINO SUPERIOR NO SETOR PRIVADO - DUMMY ESCOLARIDADE DO PAI

VARIÁVEL RESPOSTA: CONCLUINTE DO ENSINO SUPERIOR

\begin{tabular}{|c|c|c|c|c|}
\hline & Exp.(B) & B & Erro & Sig \\
\hline (Intercept) & 0.85470 & -0.15701 & 0.00812 & $2.56 \mathrm{E}-83$ \\
\hline Masculino & 0.83785 & -0.17691 & 0.00482 & $2.82 E-295$ \\
\hline Negro/Indígena & 0.99940 & -0.00060 & 0.00489 & 0.902554824 \\
\hline Renda 3 a 10 SM & 1.45273 & 0.37344 & 0.00492 & 0 \\
\hline Renda 10 a 30 SM & 1.61019 & 0.47635 & 0.00763 & 0 \\
\hline Renda acima de 30 SM & 1.61816 & 0.48129 & 0.01325 & $9.04 \mathrm{E}-289$ \\
\hline Centro-Oeste & 1.13702 & 0.12841 & 0.00775 & $1.13 E-61$ \\
\hline Nordeste & 1.01721 & 0.01707 & 0.00675 & 0.011423692 \\
\hline Norte & 0.95869 & -0.04218 & 0.01083 & $9.87 \mathrm{E}-05$ \\
\hline Sul & 1.11788 & 0.11143 & 0.00566 & $3.71 \mathrm{E}-86$ \\
\hline Trabalha1 & 0.96847 & -0.03203 & 0.00499 & $1.38 \mathrm{E}-10$ \\
\hline Idade 25-29 anos & 3.16840 & 1.15323 & 0.00584 & 0 \\
\hline Idade $30-34$ anos & 3.29818 & 1.19337 & 0.00745 & 0 \\
\hline Idade $35-39$ anos & 3.18879 & 1.15964 & 0.00933 & 0 \\
\hline Idade $40-44$ anos & 3.30639 & 1.19586 & 0.01159 & 0 \\
\hline Idade 45 ou mais anos & 3.71040 & 1.31114 & 0.01129 & 0 \\
\hline Escolaridade do pai baixa & 0.88789 & -0.11891 & 0.00511 & $1.14 \mathrm{E}-119$ \\
\hline Área saúde & 0.61290 & -0.48955 & 0.00808 & 0 \\
\hline Área exatas & 1.03965 & 0.03888 & 0.01267 & 0.002142251 \\
\hline Área engenharias & 0.68604 & -0.37681 & 0.01040 & $2.29 E-287$ \\
\hline Área sociais aplicadas & 0.79503 & -0.22938 & 0.00667 & $5.35 E-259$ \\
\hline Área agrárias & 0.69992 & -0.35679 & 0.01872 & $5.04 \mathrm{E}-81$ \\
\hline
\end{tabular}


Assim, retomando a hipótese 1, o modelo apresentado na Tabela 1 nos permite corroborar essa hipótese apenas em parte. Ao contrário do que diz a hipótese, estudantes cujos pais têm escolaridade mais alta apresentam maior probabilidade de conclusão do curso no modelo completo. Ou seja, "tudo o mais constante", origens familiares contam positivamente nas chances de conclusão. Porém, podemos dizer que em circunstâncias específicas a resiliência dos alunos com pais menos educados existe, como demonstram os resultados de um modelo sem controles.

Fica a questão se o comportamento das variáveis de origem familiar é semelhante por setor institucional. Como os tipos de cursos oferecidos e o tipo de público estudantil varia por setor, seria interessante observar o comportamento da variável escolaridade do pai quando aplicamos o mesmo modelo da Tabela 1 separadamente para instituições públicas e privadas. Aqui já iniciamos o teste da hipótese 1.1, sobre os estudantes do setor público com pais de baixa escolaridade serem mais resilientes. Para verificar os efeitos da escolaridade do pai nas chances de conclusão do curso por setor da educação, elaboramos um modelo com uma variável binária para escolaridade do pai: sendo 1 para escolaridade baixa e 0 para o resto. Classificamos como escolaridade baixa os seguintes níveis: nenhuma escolaridade e ensino fundamental $1^{5}$.

Os resultados dos modelos com as variáveis binárias estão nas Tabelas 2 e 3 e, em seguida, a Tabela 4 apresenta os efeitos marginais. O resultado da Tabela 4 resume a leitura do modelo para cada setor. No setor público, a diferença nas probabilidades de conclusão do curso entre estudantes com pais de escolaridade baixa e os demais não é estatisticamente significativa. Já no setor privado, essa diferença é estatisticamente significativa, sendo que estudantes com pais de maior escolaridade têm uma vantagem de aproximadamente $2,9 \%$ em relação aos demais na probabilidade de concluir o ensino superior.

No estudo anterior já mencionado, utilizando uma base de dados diferente da nossa e sobre a entrada no ensino superior, Prates e Collares (2014) haviam mostrado que a escolaridade do pai era importante para ambos os setores, mas parecia mais importante para o acesso ao setor público do que ao setor privado. Já o nosso estudo, que enfatiza as chances de conclusão no ensino superior e não as chances de acesso a esse nível de ensino, o resultado é o oposto. No setor privado, a escolaridade mais baixa do pai apresenta desvantagem estatisticamente significativa. Já no setor público, a diferença entre as probabilidades de estudantes com pais de escolaridade baixa e os demais não foi estatisticamente significativa. Ou seja, no setor público, as chances de concluir o curso são semelhantes entre estudantes com pais de baixa escolaridade e os demais. Já no setor privado, estu-
5. Aplicamos o mesmo modelo para cada setor separadamente e utilizamos o pacote Zelig do R para calcular efeitos marginais a partir desse modelo. 
TABELA 3

A INFLUÊNCIA DA ESCOLARIDADE DO PAI

E DA RENDA FAMILIAR NAS CHANCES DE CONCLUSÃO

DO ENSINO SUPERIOR NO SETOR PÚBLICO - DUMMY ESCOLARIDADE DO PAI

VARIÁVEL RESPOSTA: CONCLUINTE DO ENSINO SUPERIOR

\begin{tabular}{|c|c|c|c|c|}
\hline & Exp.(B) & B & Erro & Sig. \\
\hline (Intercept) & 1.18271 & 0.16781 & 0.01395 & 2.47E-33 \\
\hline Masculino & 0.84422 & -0.16935 & 0.00871 & 3.09E-84 \\
\hline Negro/Indígena & 0.97587 & -0.02443 & 0.00916 & 0.007631547 \\
\hline Renda 3 a 10 SM & 1.51141 & 0.41305 & 0.41305 & 0 \\
\hline Renda 10 a 30 SM & 1.56303 & 0.44663 & 0.01354 & $1.48 \mathrm{E}-238$ \\
\hline Renda acima de $30 \mathrm{SM}$ & 1.83342 & 0.60618 & 0.02650 & $8.43 E-116$ \\
\hline Centro-Oeste & 0.82608 & -0.19107 & 0.01442 & 4.26E-40 \\
\hline Nordeste & 0.92470 & -0.07829 & 0.01107 & $1.50 \mathrm{E}-12$ \\
\hline Norte & 1.20150 & 0.18357 & 0.01626 & 1.43E-29 \\
\hline Sul & 0.72603 & -0.32017 & 0.01174 & 1.19E-163 \\
\hline Trabalha & 1.00338 & 0.00338 & 0.00912 & 0.710951493 \\
\hline Idade $25-29$ anos & 5.02941 & 1.61530 & 0.01169 & 0 \\
\hline Idade 30-34 anos & 4.02550 & 1.39265 & 0.01801 & 0 \\
\hline Idade 35-39 anos & 3.44475 & 1.23685 & 0.02364 & 0 \\
\hline Idade $40-44$ anos & 3.44905 & 1.23810 & 0.02965 & 0 \\
\hline Idade 45 ou mais anos & 3.93533 & 1.37000 & 0.02956 & 0 \\
\hline Escolaridade do pai baixa & 0.98558 & -0.01453 & 0.01024 & 0.155752648 \\
\hline Área saude & 0.62811 & -0.46504 & 0.01322 & $3.16 \mathrm{E}-271$ \\
\hline Área exatas & 0.74171 & -0.29880 & 0.01567 & $5.01 \mathrm{E}-81$ \\
\hline Área engenharias & 0.69777 & -0.35987 & 0.01536 & $2.33 \mathrm{E}-121$ \\
\hline Área sociais aplicadas & 0.69560 & -0.36298 & 0.01190 & $1.88 \mathrm{E}-204$ \\
\hline Área agrárias & 0.60350 & -0.50500 & 0.01848 & $2.45 E-164$ \\
\hline
\end{tabular}

$\mathrm{N}=296.074$

$\mathrm{p}<0,05$

Fonte: Elaboração própria, com base nos microdados do Enade, 2008-2010 (ingressantes) e 2011-2013 (concluintes).

TABELA 4

PROBABILIDADES PREVISTAS E DIFERENÇAS DE PROBABILIDADES

PARA CONCLUSÃO DO ENSINO SUPERIOR, CONSIDERANDO

A ESCOLARIDADE DO PAI E SETOR DA EDUCAÇÃO

\begin{tabular}{|l|c|c|}
\cline { 2 - 3 } \multicolumn{1}{c|}{} & Setor Privado & Setor Público \\
\hline Escolaridade do pai > baixa & 0,4591 & 0,6197 \\
\hline Escolaridade do Pai = baixa & 0,4887 & 0,6232 \\
\hline Diferença & $-0,0295^{* *}$ & $-0,0034$ (não sig.) \\
\hline
\end{tabular}

$p<0,05$

Fonte: Elaboração própria, com base nos microdados do Enade, 2008-2010 (ingressantes) e 2011-2013 (concluintes). 
TABELA 5

A INFLUÊNCIA DA ESCOLARIDADE DO PAI

NAS CHANCES DE CONCLUSÃO DO ENSINO SUPERIOR.

MODELO COM INTERAÇÃO ENTRE BAIXA ESCOLARIDADE

DO PAI E CURSOS DE ALTO RETORNO ECONÔMICO

VARIÁVEL RESPOSTA: CONCLUINTE DO ENSINO SUPERIOR

\begin{tabular}{|c|c|c|c|c|}
\hline & Exp.(B) & B & Erro & Sig \\
\hline (Constante) & 0.93683 & -0.06525 & 0.00704 & $1.79 \mathrm{E}-20$ \\
\hline Masculino & 0.86405 & -0.14612 & 0.00421 & $6.86 \mathrm{E}-264$ \\
\hline Negro/Indígena & 0.99156 & -0.00847 & 0.0043 & 0.048996 \\
\hline Renda 3 a $10 \mathrm{SM}$ & 1.62549 & 0.48581 & 0.00667 & 0 \\
\hline Renda 10 a 30 SM & 1.46677 & 0.38306 & 0.00434 & 0 \\
\hline Renda acima de 30 SM & 1.67345 & 0.51489 & 0.01188 & 0 \\
\hline Centro-Oeste & 1.09729 & 0.09285 & 0.00675 & $5.36 \mathrm{E}-43$ \\
\hline Nordeste & 1.08968 & 0.08588 & 0.00551 & $9.19 E-55$ \\
\hline Norte & 1.16634 & 0.15387 & 0.00871 & $6.72 \mathrm{E}-70$ \\
\hline Sul & 1.04204 & 0.04118 & 0.00507 & 4.67E-16 \\
\hline Trabalha & 0.93474 & -0.06748 & 0.00439 & $2.96 E-53$ \\
\hline Idade $25-29$ anos & 3.47202 & 1.24474 & 0.00518 & 0 \\
\hline Idade $30-34$ anos & 3.36276 & 1.21276 & 0.00684 & 0 \\
\hline Idade 35-39 anos & 3.20457 & 1.16458 & 0.00864 & 0 \\
\hline Idade $40-44$ anos & 3.32211 & 1.2006 & 0.01077 & 0 \\
\hline Idade 45 ou mais anos & 3.7708 & 1.32729 & 0.01053 & 0 \\
\hline Escolaridade do pai baixa & 0.94685 & -0.05462 & 0.00511 & $1.14 \mathrm{E}-26$ \\
\hline Retorno alto & 0.89999 & -0.10537 & 0.00586 & $3.08 \mathrm{E}-72$ \\
\hline Área saúde & 0.59906 & -0.51239 & 0.00686 & 0 \\
\hline Área exatas & 0.91792 & -0.08564 & 0.00975 & $1.59 \mathrm{E}-18$ \\
\hline Área engenharias & 0.78324 & -0.24432 & 0.00979 & $2.11 \mathrm{E}-137$ \\
\hline Área sociais aplicadas & 0.75549 & -0.28039 & 0.00584 & 0 \\
\hline Área agrárias & 0.75755 & -0.27767 & 0.01343 & $5.29 E-95$ \\
\hline $\begin{array}{l}\text { Escolaridade do pai baixa: } \\
\text { retorno alto }\end{array}$ & 0.80295 & -0.21946 & 0.00966 & $3.46 \mathrm{E}-114$ \\
\hline
\end{tabular}

dantes com pais de baixa escolaridade têm menores chances de concluir os cursos que os demais. Assim, esses modelos mostram que o acesso mais competitivo pode estar "filtrando" mais o alunado do setor público do que o do setor privado de maneira agregada, reduzindo o impacto das origens familiares na conclusão dos cursos no setor público, mais do que para os ingressantes no setor privado, onde a renda familiar, principalmente, contaria mais fortemente para as chances de conclusão ${ }^{6}$.

6. Não comparamos aqui alunos que ingressaram através de políticas de ação afirmativa com os demais, nem aqueles que ingressaram através de programas como o Prouni, que facilita o financiamento da educação desses estudantes no setor privado. Pode haver diferenças significativas entre esses alunos que não poderíamos capturar aqui com os dados utilizados. 
A hipótese 2 relaciona a escolaridade do pai com o retorno econômico dos cursos. Para testá-la, elaboramos um modelo com uma interação entre baixa escolaridade do pai (nenhuma e ensino fundamental 1) e cursos de alto retorno - Tabela 5.

O comportamento das varáveis de controle nesse modelo é muito semelhante ao modelo completo (Tabela 1). A única variável que apresenta um resultado diferente é cor/raça. No modelo dois, negros/indígenas passam a ter desvantagem nas chances de concluir o curso, embora seja bem pequena, cerca de $0,8 \%$ de chances a menos. Uma explicação possível para isso é que os negros/indígenas possuem menores chances de concluir cursos de alto retorno econômico, assim, quando o impacto do curso no mercado de trabalho é controlado, a vantagem destes, que se encontraria nos cursos de mais baixo retorno econômico, mais numerosos, desapareceria.

Este modelo mostra que mesmo quando diferenciamos os efeitos de escolaridade do pai por retorno econômico dos cursos (retorno alto versus retorno médio/ baixo), os estudantes cujos pais têm baixa escolaridade têm menores chances de conclusão. De fato, o coeficiente para escolaridade baixa no modelo indica o efeito quando o retorno econômico alto é igual a zero, ou seja, o efeito para cursos de retorno médio/baixo. Uma vez que esse resultado é negativo e significativo, concluímos que, dentro desse grupo de cursos (de médio e baixo retorno), os estudantes com pais de menor escolaridade apresentam menores chances de conclusão.

Para facilitar a interpretação do termo interativo, calculamos os efeitos marginais das interações. A seguir, apresentamos as probabilidades previstas e as diferenças de probabilidades para as combinações entre escolaridade do pai e retorno econômico dos cursos.

TABELA 6

PROBABILIDADES PREVISTAS E DIFERENÇAS DE PROBABILIDADES PARA CONCLUSÃO DO ENSINO SUPERIOR, CONSIDERANDO ESCOLARIDADE

DO PAI E RETORNO ECONÔMICO DOS CURSOS

Escolaridade do Pai $>$ baixa $\quad$ Escolaridade do Pai = baixa

\begin{tabular}{|c|c|c|}
\hline Cursos de médio e baixo retorno & 0,56223 & 0,54878 \\
\hline Cursos de alto retorno & 0,53616 & 0,46767 \\
\hline Diferença & $-0,02607 * *$ & $-0,08111^{* *}$ \\
\hline
\end{tabular}


A partir da Tabela 6, observamos que os estudantes com pais de baixa escolaridade apresentam probabilidade de conclusão do ensino superior maior nos cursos de médio e baixo retorno do que nos cursos de alto retorno. A diferença entre as probabilidades de conclusão é estatisticamente significativa e de magnitude de aproximadamente $8,1 \%$. Portanto, embora pais com escolaridade mais baixa diminuírem as chances de conclusão dos cursos em geral, esse fator parece ser mais determinante para os cursos de alto retorno econômico. Assim, os dados corroboram a hipótese 2 , de que as chances de estudantes com pais de baixa escolaridade concluir em os cursos são maiores para cursos de médio/baixo retorno do que para cursos de alto retorno.

Em relação à hipótese 3 , vimos, no primeiro modelo, apresentado na Tabela 1 , que as chances de conclusão dos cursos aumenta para aqueles que possuem uma renda familiar superior a 3 salários mínimos. Esse resultado pode ser considerado um primeiro indício para a confirmação da hipótese 3 .

TABELA 7

PROBABILIDADES PREVISTAS E DIFERENÇAS

DE PROBABILIDADES PARA CONCLUSÃO DO ENSINO

SUPERIOR, COMPARANDO RENDA FAMILIAR DE ATÉ 3 SM

E RENDA FAMILIAR DE 3 A 10 SM

\begin{tabular}{|l|c|}
\cline { 2 - 2 } \multicolumn{1}{l|}{} & Todos os cursos \\
\hline Renda até 3 SM & 0,4587 \\
\hline Renda de 3 a 10 SM & 0,5466 \\
\hline Diferença & $0,0879 * *$ \\
\hline ** $p<0,05$ \\
Fonte: Elaboração própria, a partir dos microdados Enade 2008-2010 (ingressantes) e 2011- \\
2013 (concluintes).
\end{tabular}

TABELA 8

PROBABILIDADES PREVISTAS E DIFERENÇAS

DE PROBABILIDADES PARA CONCLUSÃO DO ENSINO

SUPERIOR, COMPARANDO RENDA FAMILIAR DE ATÉ 3 SM

E RENDA FAMILIAR DE 10 A 30 SM

\begin{tabular}{|l|c|}
\hline \multicolumn{1}{l|}{} & Todos os cursos \\
\hline Renda até 3 SM & 0,4589 \\
\hline Renda de 3 a 10 SM & 0,5538 \\
\hline Diferença & $0,0948^{* *}$ \\
** p < 0,05 \\
Fonte: Elaboração própria, a partir dos microdados Enade 2008-2010 (ingressantes) e 2011- \\
2013 (concluintes).
\end{tabular}


TABELA 9

PROBABILIDADES PREVISTAS E DIFERENÇAS

DE PROBABILIDADES PARA CONCLUSÃO DO ENSINO

SUPERIOR, COMPARANDO RENDA FAMILIAR DE ATÉ 3 SM

E RENDA FAMILIAR ACIMA DE 30 SM

\begin{tabular}{|l|c|}
\cline { 2 - 2 } \multicolumn{1}{c|}{} & Todos os cursos \\
\hline Renda até 3 SM & 0,4589 \\
\hline Renda acima de 30 SM & 0,5537 \\
\hline Diferença & $0,0948^{* *}$ \\
\hline
\end{tabular}

\section{** $\mathrm{p}<0,05$}

Fonte: Elaboração própria, a partir dos microdados Enade 2008-2010 (ingressantes) e 2011-2013 (concluintes).

\section{TABELA 10}

A INFLUÊNCIA DA RENDA FAMILIAR NAS CHANCES DE CONCLUSÃO DO ENSINO SUPERIOR NO SETOR PRIVADO - MODELO COM DUMMY PARA RENDA FAMILIAR

VARIÁVEL RESPOSTA: CONCLUINTE DO ENSINO SUPERIOR

\begin{tabular}{|c|c|c|c|c|}
\hline & Exp.(B) & B & Erro & Sig \\
\hline (Intercept) & 0.72762 & -0.31798 & 0.01216 & 8.94E-151 \\
\hline Masculino & 0.84647 & -0.16668 & 0.00480 & $1.19 E-263$ \\
\hline Negro/Indígena & 0.98983 & -0.01023 & 0.00488 & 0.036236 \\
\hline Renda alta1 & 1.16106 & 0.14934 & 0.00662 & $1.14 \mathrm{E}-112$ \\
\hline Centro-Oeste & 1.12447 & 0.11731 & 0.00774 & $6.15 E-52$ \\
\hline Nordeste & 0.99359 & -0.00643 & 0.00674 & 0.340487 \\
\hline Norte & 0.94933 & -0.05200 & 0.01081 & $1.52 \mathrm{E}-06$ \\
\hline Sul & 1.11218 & 0.10633 & 0.00566 & $7.27 E-79$ \\
\hline Trabalha1 & 1.01203 & 0.01196 & 0.00501 & 0.016959 \\
\hline Idade25-29 anos & 3.20172 & 1.16369 & 0.00584 & 0 \\
\hline Idade30-34 anos & 3.39388 & 1.22197 & 0.00746 & 0 \\
\hline Idade35-39 anos & 3.34610 & 1.20780 & 0.00934 & 0 \\
\hline Idade40-44 anos & 3.53886 & 1.26381 & 0.01160 & 0 \\
\hline Idade 45 ou mais anos & 4.05241 & 1.39931 & 0.01132 & 0 \\
\hline Escolaridade do pai-EF1 & 1.20529 & 0.18672 & 0.01021 & $9.31 \mathrm{E}-75$ \\
\hline Escolaridade do pai-EF2 & 1.17537 & 0.16159 & 0.01116 & $1.56 \mathrm{E}-47$ \\
\hline Escolaridade do pai- EM & 1.40321 & 0.33876 & 0.01058 & 4.00E-225 \\
\hline Escolaridade do pai- ES/PG & 1.73660 & 0.55193 & 0.01130 & 0 \\
\hline Área saúde & 0.62129 & -0.47595 & 0.00806 & 0 \\
\hline Área exatas & 1.07738 & 0.07453 & 0.01263 & 3.59E-09 \\
\hline Área engenharias & 0.71526 & -0.33512 & 0.01035 & $7.98 \mathrm{E}-230$ \\
\hline Área sociais aplicadas & 0.81087 & -0.20965 & 0.00665 & $2.94 \mathrm{E}-218$ \\
\hline Área agrárias & 0.71767 & -0.33174 & 0.01870 & 2.19E-70 \\
\hline
\end{tabular}

$\mathrm{N}=952.979$

$\mathrm{p}<0,05$

Fonte: Elaboração própria, com base nos microdados do Enade, 2008-2010 (ingressantes) e 2011-2013 (concluintes). 
TABELA 11

A INFLUÊNCIA DA RENDA FAMILIAR NAS CHANCES DE CONCLUSÃO DO ENSINO SUPERIOR NO SETOR PÚBLICO.

MODELO COM DUMMY PARA RENDA FAMILIAR

VARIÁVEL RESPOSTA: CONCLUINTE DO ENSINO SUPERIOR

\begin{tabular}{|c|c|c|c|c|}
\hline & Exp.(B) & B & Erro & Sig. \\
\hline (Intercept) & 1.16565 & 0.15328 & 0.02233 & $6.66 \mathrm{E}-12$ \\
\hline Masculino & 0.85464 & -0.15708 & 0.00868 & $3.09 E-73$ \\
\hline Negro/Indígena & 0.96514 & -0.03548 & 0.00914 & 0.000103 \\
\hline renda alta1 & 1.15148 & 0.14105 & 0.01205 & 1.19E-31 \\
\hline Centro-Oeste & 0.82133 & -0.19683 & 0.01438 & $1.25 \mathrm{E}-42$ \\
\hline Nordeste & 0.90081 & -0.10446 & 0.01102 & $2.63 E-21$ \\
\hline Norte & 1.18167 & 0.16693 & 0.01620 & $6.89 E-25$ \\
\hline Sul & 0.72854 & -0.31671 & 0.01172 & $9.66 \mathrm{E}-161$ \\
\hline Trabalha1 & 1.04237 & 0.04150 & 0.00911 & $5.29 \mathrm{E}-06$ \\
\hline Idade $25-29$ anos & 5.05701 & 1.62078 & 0.01167 & 0 \\
\hline Idade $30-34$ anos & 4.16270 & 1.42616 & 0.01800 & 0 \\
\hline Idade $35-39$ anos & 3.66329 & 1.29836 & 0.02362 & 0 \\
\hline Idade $40-44$ anos & 3.73062 & 1.31657 & 0.02962 & 0 \\
\hline Idade 45 ou mais anos & 4.35939 & 1.47233 & 0.02954 & 0 \\
\hline Escolaridade do pai-EF1 & 1.13224 & 0.12420 & 0.01967 & $2.74 \mathrm{E}-10$ \\
\hline Escolaridade do pai-EF2 & 1.04137 & 0.04054 & 0.02152 & 0.059566 \\
\hline Escolaridade do pai-EM & 1.22996 & 0.20698 & 0.02006 & $5.80 \mathrm{E}-25$ \\
\hline Escolaridade do pai- ES/PG & 1.44650 & 0.36915 & 0.02099 & $3.26 \mathrm{E}-69$ \\
\hline Área saúde & 0.64699 & -0.43543 & 0.01315 & $2.10 \mathrm{E}-240$ \\
\hline Área exatas & 0.75675 & -0.27872 & 0.01562 & $2.95 \mathrm{E}-71$ \\
\hline Área engenharias & 0.72087 & -0.32730 & 0.01530 & $1.66 \mathrm{E}-101$ \\
\hline Área sociais aplicadas & 0.72127 & -0.32674 & 0.01182 & $3.60 \mathrm{E}-168$ \\
\hline Área agrárias & 0.61131 & -0.49215 & 0.01845 & $7.62 E-157$ \\
\hline
\end{tabular}

TABELA 12

PROBABILIDADES PREVISTAS E DIFERENÇAS DE PROBABILIDADES PARA CONCLUSÃO DO ENSINO SUPERIOR, POR RENDA FAMILIAR E SETOR DA EDUCAÇÃO

\begin{tabular}{|l|c|c|}
\hline \multicolumn{1}{l|}{} & Setor Privado & Setor Público \\
\hline $\begin{array}{l}\text { Renda familiar média/baixa } \\
(<10 \text { SM) }\end{array}$ & 0,4184 & 0,5636 \\
\hline $\begin{array}{l}\text { Renda familiar alta } \\
(>10 \mathrm{SM})\end{array}$ & 0,4551 & 0,5981 \\
\hline Diferença & $0,0366^{* *}$ & $0,0344^{* *}$ \\
\hline
\end{tabular}

Fonte: Elaboração própria, com base nos microdados do Enade, 2008-2010 (ingressantes) e 2011-2013 (concluintes). 
De forma complementar, calculamos as probabilidades previstas e as diferenças de probabilidades para estudantes com renda familiar de até 3 salários mínimos para três faixas de renda. Os resultados estão reportados nas três tabelas abaixo. As diferenças nas probabilidades de conclusão são estatisticamente significativas e indicam vantagem para aqueles estudantes pertencentes a qualquer faixa de renda familiar superior a 3 salários mínimos, confirmando a hipótese 3.

\section{TABELA 13}

A INFLUÊNCIA DA RENDA FAMILIAR NAS CHANCES

DE CONCLUSÃO DO ENSINO SUPERIOR.

MOdELO COM INTERAÇÃO ENTRE RENDA FAMILIAR ALTA

E CURSOS COM RETORNO ECONÔMICO ALTO

VARIÁVEL RESPOSTA: CONCLUINTE DO ENSINO SUPERIOR

\begin{tabular}{|c|c|c|c|c|}
\hline & Exp.(B) & B & Erro & Sig. \\
\hline (Constante) & 0.84575 & -0.16753 & 0.01055 & 8.04E-57 \\
\hline Masculino & 0.87065 & -0.13851 & 0.0042 & $1.54 \mathrm{E}-238$ \\
\hline Negro/Indígena & 0.9823 & -0.01786 & 0.0043 & $3.22 \mathrm{E}-05$ \\
\hline Escolaridade do pai- EF1 & 1.17419 & 0.16058 & 0.00901 & 5.51E-71 \\
\hline Escolaridade do pai- EF2 & 1.13082 & 0.12294 & 0.00986 & $1.11 \mathrm{E}-35$ \\
\hline Escolaridade do pai- EM & 1.35921 & 0.30691 & 0.00931 & $4.11 E-238$ \\
\hline Escolaridade do pai- ES/PG & 1.69853 & 0.52976 & 0.00992 & 0 \\
\hline Centro-Oeste & 1.08683 & 0.08327 & 0.00674 & $4.68 \mathrm{E}-35$ \\
\hline Nordeste & 1.06111 & 0.05931 & 0.0055 & $4.01 \mathrm{E}-27$ \\
\hline Norte & 1.15086 & 0.14051 & 0.00869 & $7.79 E-59$ \\
\hline Sul & 1.03936 & 0.0386 & 0.00506 & $2.41 \mathrm{E}-14$ \\
\hline Idade 25-29 anos & 3.50979 & 1.25556 & 0.00518 & 0 \\
\hline Idade $30-34$ anos & 3.46918 & 1.24392 & 0.00684 & 0 \\
\hline Idade 35-39 anos & 3.37204 & 1.21552 & 0.00864 & 0 \\
\hline Idade $40-44$ anos & 3.55827 & 1.26927 & 0.01076 & 0 \\
\hline Idade 45 ou mais anos & 4.1036 & 1.41187 & 0.01053 & 0 \\
\hline Trabalha & 0.97622 & -0.02407 & 0.0044 & $4.44 \mathrm{E}-08$ \\
\hline Renda alta & 1.15637 & 0.14528 & 0.00796 & $2.04 \mathrm{E}-74$ \\
\hline Retorno alto & 0.83864 & -0.17597 & 0.0057 & 4.37E-209 \\
\hline Área saúde & 0.60719 & -0.49892 & 0.00683 & 0 \\
\hline Área exatas & 0.93582 & -0.06633 & 0.00971 & 8.47E-12 \\
\hline Área engenharias & 0.81581 & -0.20357 & 0.00977 & $2.52 E-96$ \\
\hline Área sociais aplicadas & 0.7701 & -0.26123 & 0.00581 & 0 \\
\hline Área agrárias & 0.76597 & -0.26661 & 0.01343 & $9.19 E-88$ \\
\hline Renda alta: retorno alto & 1.03462 & 0.03404 & 0.01096 & 0.001906 \\
\hline
\end{tabular}


TABELA 14

PROBABILIDADES PREVISTAS E DIFERENÇAS DE

PROBABILIDADES PARA CONCLUSÃO DO ENSINO SUPERIOR,

POR TIPO DE CURSOS E POR RENDA FAMILIAR

Curso de retorno médio/baixo Curso de retorno alto

\begin{tabular}{|c|c|c|}
\hline $\begin{array}{l}\text { Renda média/baixa } \\
\text { (até } 10 \text { SM) }\end{array}$ & 0,4922 & 0,4483 \\
\hline $\begin{array}{l}\text { Renda alta } \\
\text { (acima de } 10 \text { SM) }\end{array}$ & 0,5285 & 0,4930 \\
\hline Diferença & $0,0362 * *$ & $0,0446 * *$ \\
\hline
\end{tabular}

Observe que para a faixa de renda de 3 a 10 SM quando comparada à faixa de renda até $3 \mathrm{SM}$, a diferença nas probabilidades de concluir o curso é de aproximadamente $8,7 \%$. Para as faixas de renda de10 a 30 SM e acima de 30 SM, essa diferença nas probabilidades é ainda maior, aproximadamente 9,5\% em ambos os casos, quando comparada à faixa de renda mais baixa (até $3 \mathrm{SM}$ ). Portanto, a renda familiar continua sendo uma variável bastante importante para a conclusão do ensino superior, mesmo com todos os controles empregados no modelo. Para testar a hipótese, elaboramos um modelo com uma variável binária para renda familiar, sendo 1 para renda familiar alta (acima de 10 salários mínimos) e 0 para renda familiar abaixo de 10 salários mínimos. O modelo foi aplicado para cada setor separadamente (Tabelas 10 e 11). A partir dos modelos, calculamos os efeitos marginais (Tabela 12).

A Tabela 12 é uma síntese do resultado do modelo para cada setor, e não indica grandes diferenças por setor na hipótese testada. Estudantes de renda familiar mais elevada apresentam maior probabilidade de concluírem os cursos em ambos os setores. As diferenças de probabilidade em cada setor são bem próximas. No setor privado, a diferença nas probabilidades de conclusão do curso entre estudantes de renda familiar alta e os demais é de aproximadamente $3,6 \%$. No setor público, essa diferença é cerca de 3,4\%.

Por fim, resta-nos testar a hipótese sobre o retorno econômico dos cursos. Para testar essa hipótese, elaboramos um modelo com interação entre renda familiar alta (categorias de 10 a 30 SM e acima de 30 SM) e cursos de retorno econômico alto (Tabela 13). A tabela seguinte apresenta os resultados do modelo. Os coeficientes são todos estatisticamente significativos $(p<0,05)$. O coeficiente para retorno econômico alto no modelo indica o efeito quando a renda familiar alta é igual a zero, ou seja, o efeito para rendas mais baixas. Uma vez que esse resultado 
é negativo e significativo, concluímos que estudantes de renda familiar mais baixa têm menores chances de concluir os cursos de maior retorno econômico. Os efeitos marginais desse modelo estão mostrados na tabela 14.

De acordo com a Tabela 14, ter uma renda alta aumenta as chances de concluir o ensino superior qualquer que seja o tipo de curso (baixo/médio ou alto retorno econômico). Observe que para os cursos de alto retorno, a diferença de probabilidades entre ter renda alta e ter renda média/baixa é de aproximadamente 4,5\%, enquanto para os cursos de médio/baixo retorno esse valor é de aproximadamente 3,6\%. Esses percentuais indicam que, embora dispor uma renda elevada seja importante para os dois tipos de curso, esse fator parece ser um pouco mais decisivo para os cursos de alto retorno econômico.

\section{Considerações finais}

Muito se tem escrito sobre o impacto das origens sociais no acesso ao ensino superior, tanto internacionalmente como no Brasil. Porém, estudos quantitativos sobre as chances de conclusão dos estudantes que entram nesse nível de ensino são menos frequentes. Neste artigo, procuramos dar uma contribuição ao entendimento dos mecanismos de permanência no ensino superior brasileiro ao mostrar a influência da origem familiar nas chances de concluir cursos em diversas áreas, e testar essa influência de acordo com os retornos econômicos estimados de cada curso no mercado de trabalho. Fizemos uma comparação entre ingressantes e concluintes de diversos cursos com base nos dados do Enade e utilizamos modelos de regressão logística para discutir cinco hipóteses relacionadas às origens sociais dos estudantes.

A partir das hipóteses elaboradas, foi possível verificar a influência da origem social do estudante na conclusão dos cursos. Diante dos resultados encontrados para as hipóteses 3, 4 e 5, ficou evidente a importância da renda familiar na conclusão do ensino superior, mesmo considerando os diferentes setores de ensino e os cursos com retornos econômicos distintos. Em geral, estudantes de rendas familiares mais elevadas têm mais chances de conclusão. Os efeitos da escolaridade do pai também são determinantes das chances de conclusão, especialmente nos cursos de alto retorno econômico. Porém, no modelo sem controles, verificamos que, especialmente para o setor público, estudantes de pais com escolaridade mais baixa, uma vez garantido o acesso, possuem mais chances de conclusão do que os demais. Isso pode ser explicado por estes já terem atravessado o filtro da entrada, que seleciona apenas aqueles com mais recursos - sejam individuais, econômicos ou familiares - para a conclusão dos cursos. 
Teorias da reprodução social (ver Vilela e Collares, 2009) indicam que a instituição escolar acaba por reproduzir desigualdades de origem, quando o status ocupacional ou econômico final dos egressos do sistema escolar são levados em conta. Em nossa investigação, os mecanismos de produção dessa desigualdade surgem de forma contundente no ensino superior brasileiro, onde os alunos de maior renda familiar têm não apenas maiores chances de concluir os cursos que iniciam como ainda de escolher cursos com mais alto retorno econômico no mercado de trabalho.

Mais: alunos com pais de baixa escolaridade e alunos negros/indígenas têm menor chances de concluir cursos de alto retorno econômico.

Essa seleção para cursos de maior retorno econômico não é generalizável para sistemas de ensino superior em todo o mundo. François Dubet (2012), ao investigar a ligação entre origens e destinos sociais para diversos países, mostra, por exemplo, que a maneira como o sistema escolar é organizado (e.g. com um tronco comum longo ou com trilhas diferentes de aprendizagem), impacta na forma como as credenciais educacionais são valorizadas no mercado de trabalho. Na investigação de lanelli et alii (2018) sobre o sistema escolar escocês, os autores mostram que alunos de origem social mais alta escolhem instituições de maior prestígio, porém alunos de origem mais baixa possuem maior tendência a escolher cursos de maior retorno econômico no mercado de trabalho.

No caso brasileiro, mostramos que a renda familiar principalmente e, em alguma medida, a educação dos pais continuam a exercer influência no destino dos indivíduos mesmo após a entrada para a universidade ou faculdade, impactando nas escolhas de cursos e nas chances de conclusão dos mesmos. A recente democratização do acesso ao ensino superior, com políticas de financiamento e de ação afirmativa que ampliaram em alguma medida o acesso de setores menos privilegiados a esse nível de ensino, pode ter causado alguma redução no impacto das origens sociais no acesso e até nos destinos finais dos graduandos no mercado. Porém, muito ainda precisa ser feito não apenas para ampliar essa democratização do acesso, mas, como procuramos discutir aqui, para aumentar as chances de permanência e conclusão dos alunos, pois tais chances ainda são fortemente influenciadas pela origem social dos mesmos. 


\section{Referências}

ALMEIDA, L. et alii. Democratização do acesso e do sucesso no ensino superior: uma reflexão a partir das realidades de Portugal e do Brasil. Avaliação, v. 17, n. 3, p. 899-920, Nov. 2012.

ANDRADE, C. Y. Acesso ao ensino superior no Brasil: equidade e desigualdade social. Revista Ensino Superior Unicamp, n. 6, p. 18-27, Jul./Set. 2012.

ANDRADE, S. M. et alii. Análise da evasão de alunos dos cursos de profissionalização da área de enfermagem no Paraná. Ciência, Cuidado e Saúde, v. 6, n. 4. 2007.

ANDRIOLA, W. B. et alii. Opiniões de docentes e de coordenadores acerca do fenômeno da evasão discente dos cursos de graduação da Universidade Federal do Ceará (UFC). Ensaio: Avaliação e Políticas Públicas em Educação, v. 14, n. 52, p. 365-382, 2006.

ARUM, Richard; GAMORAN, Adam; SHAVIT, Yossi. More inclusion than diversion: expansion, differentiation, and market structure in higher education. In: SHAVIT, Yossi et alii (Orgs.). Stratification in higher education: a comparative study. Stanford (CA): Stanford University Press, 2007.

AYALON, H.; YOGEV, A. Field of study and students' stratification in an expanded system of higher education: the case of Israel. European Sociological Review, v. 21, n. 3, p. 211-241, Jul. 2005.

AYALON, H. et alii. Diversification and inequality in higher education: a comparison of Israel and the United States. Sociology of Education, v. 81, n. 3, p. 211-241. 2008.

BARBOSA, M. L. Destinos, escolhas e a democratização do ensino superior. Política \& Sociedade, v. 14, n. 31, Set./Dez. 2015.

— (org.). Ensino superior: expansão e democratização. Coleção "Sociologia e Antropologia". Rio de Janeiro: 7 Letras, 2014.

BELTRÃO, K. et alii. Diferenciais socioeconômicos dos concluintes das diferentes áreas. In: LETICHEVSKY, A. C. et alii (Orgs.). Enade: quarto recortes - quatro visões. Rio de Janeiro: Fundação Cesgranrio, 2016.

BERTOLIN, Julio et alii. Os cursos de graduação podem compensar a falta de capital cultural e background de estudantes? Educação e Pesquisa, v. 45, e185453, p.1-18, 2019. 
BLOSSFELD, H-P.; SHAVIT, Y. Persisting barriers: changes in educational opportunities in thirteen countries. In: SHAVIT, Y.; BLOSSFELD, H-P. Persistent inequality: changing educational attainment in thirteen countries. Denver (CO): Westview Press, 1993.

BRITTO, L. P. L. et alii.Conhecimento e formação nas IES periféricas - perfil do aluno "novo" da educação superior. Avaliação, v. 13, n. 3, p. 777-791, Nov. 2008.

CARDOSO, C. B. Efeitos da política de cotas na Universidade de Brasília: uma análise do rendimento e da evasão. Dissertação (Mestrado em Educação) - Universidade de Brasília, Brasília (DF), 2008.

CARVALHAES, Flavio; RIBEIRO, Carlos Antônio C. Estratificação horizontal na educação superior no Brasil: desigualdades de classe, gênero e raça em um contexto de expansão educacional. Tempo Social, Revista de Sociologia da USP, v. 31, n. 1, p. 195-233, 2019.

CARVALHO, C. H. A. Estudo comparado sobre a expansão do ensino superior: Brasil e Estados Unidos. In: LÓPEZ SEGREGA, Francisco (Org.). Escenarios mundiales de la educación superior. Análisis global y estudios de casos. Buenos Aires: Clacso, 2007.

CARVALHO, C.; OLIVEIRA, V. W. N. Evasão na licenciatura: estudo de caso. Revista Trilhas da História, v. 3, n. 6, p. 97-112, Jan./Jun. 2014.

COLLARES, A. C. Inequality and the expansion or higher education in Brazil from 1982 to 2006. PhD Dissertation. University of Wisconsin-Madison, 2010.

CORBUCCI, P. L. Desafios da educação superior e desenvolvimento no Brasil. Texto para discussão n. 1287. Brasília: Ipea, 2007.

DUBET, François et alii. As desigualdades escolares antes e depois da escola: organização escolar e influência dos diplomas. Sociologias, Ano 14, n. 29, Jan./Abr., p. 22-70, 2012.

FERNANDES, D. C. Race, socioeconomic development and the educational stratification process in Brazil. Research in Social Stratification and Mobility, v. 22, p. 365-422, 2004.

GAIOSO, N. P. de L. O fenômeno da evasão escolar na educação superior no Brasil. Dissertação (Mestrado em Educação) - Programa de Pós-Graduação em Educação da Universidade Católica de Brasília, Brasília (DF), 2005. 
GARZELLA, F. A. C. A disciplina de Cálculo I: análise das relações entre as práticas pedagógicas do professor e seus impactos nos alunos. Tese (doutorado) - Universidade Estadual de Campinas (Unicamp), Faculdade de Educação, Campinas (SP), 2013.

GERBER, Theodore. P.; CHEUNG, Sin Yi. Horizontal stratification in postsecondary education: forms, explanations and implications. Annual Review of Sociology, v. 34, n. 1, p. 299-318, 2008.

GUIMARÃES, Raquel Rangel de Meireles; RIOS-NETO, Eduardo Luiz Gonçalves. Comparação entre metodologias de idade-período-coorte para o estudo de uma medida da progressão escolar no Brasil. Rev. bras. Estud. Popul. [online], v. 28, n. 2, p.349-367, 2011.

HASENBALG, C.; SILVA, N. V. Origens e destinos: desigualdades sociais ao longo da vida. Rio de Janeiro: Iuperj/Ucam; Topbooks; Faperj, 2003.

IANELLI, C.; GAMORAN, A.; PATERSON, L. Fields of study: Horizontal or vertical differentiation within higher education sectors? Research in Social Stratification and Mobility, v. 57, p. 11-23, Oct. 2018.

INSTITUTO NACIONAL DE ESTUDOS E PESQUISAS ANÍSIO TEIXEIRA (INEP). Sinopse estatística da educação superior 2015. Brasília: Inep, 2016. Disponível em: <http:// por-tal.inep.gov.br/web/guest/sinopses-estatisticas-da-educacao-superior>.

LOBO, M. B. de C. M. Panorama da evasão no ensino superior brasileiro: aspectos gerais das causas e soluções. Abmes Cadernos, n. 25, p. 9-58, Dez. 2012.

LUCAS, S. R. Effectively maintained inequality: education transitions, track mobility, and social background effects. The American Journal of Sociology, v. 106, n. 6, p. 1642-1690, 2001.

MASSI, L.; VILLANI, A. A case of countertrend: low dropout rates among chemistry degree students explained by disposition and integration. Educação e Pesquisa, v. 41, n. 4, p. 975-992, Out./Dez. 2015.

MONT'ALVÃO, Arnaldo. Estratificação educacional no Brasil do século XXI. Dados, v. 54, n. 2, p. 389-430, 2011.

NERI, M. O retorno da educação no mercado de trabalho. Rio de Janeiro: Centro de Políticas Educacionais/Fundação Getúlio Vargas, 2005.

NUNES, E. Desafio estratégico da política pública: o ensino superior brasileiro. Revista Administração Pública, n. 41, p. 103-147, 2007. 
PRATES, A. A.; COLLARES, A. C. Desigualdade e expansão do ensino superior na sociedade contemporânea: o caso brasileiro do final do século XX ao princípio do século XXI. Belo Horizonte (MG): Editora Fino Traço. 2014.

RAFTERY, A. E.; HOUT, M. Maximally maintained inequality: expansion, reform, and opportunity in irish education, 1921-75. Sociology of Education, v. 66, n. 1, p. 41-62, 1993.

RIBEIRO, C. A. Desigualdade de oportunidades e resultados educacionais no Brasil. Dados, v. 54, n. 1, p. 41-87, 2011.

- Desigualdade de oportunidades educacionais no Brasil: classe, gênero e raça. In: RIBEIRO, C. A. Desigualdade de oportunidades no Brasil. Belo Horizonte: Argumentum, 2009.

RIOS-NETO, Eduardo Luiz G.; GUIMARÃES, Raquel Rangel de M. The demography of education in Brazil: inequality of educational opportunities based on Grade Progression Probability (1986-2008). Vienna Yearbook of Population Research 2010, v. 8, p. 283-312, 2010.

RISTOFF, D. O novo perfil do campus brasileiro: uma análise do perfil socioeconômico do estudante de graduação. Avaliação, v. 19, n. 3, p. 723-47, Nov. 2014.

SALATA, André. Ensino Superior no Brasil das últimas décadas: redução nas desigualdades de acesso? Tempo Soc., São Paulo , v. 30, n. 2, p. 219-253, Aug. 2018.

SILVA, G. P. Análise de evasão no ensino superior: uma proposta de diagnóstico de seus determinantes. Avaliação, v. 18, n.2, p. 311-33, Jul. 2013.

SILVA, N. V. Expansão escolar e estratificação educacional no Brasil. In. HASENBALG, C.; SILVA, N. V. Origens e destinos: desigualdades sociais ao longo da vida. Rio de Janeiro: Iuperj/Ucam; Topbooks; Faperj, 2003.

TORCHE, Florencia; COSTA-RIBEIRO, Carlos. Parental wealth and children's outcomes over the life-course in Brazil: a propensity score matching analysis. Research in Social Stratification and Mobility, v. 30, p. 79-96, 2012.

- Pathways of change in social mobility: industrialization, education and growing fluidity in Brazil. Research in Social Stratification and Mobility, v. 28, n. 3, p. 291-307, 2010. 
TRIVENTI, M.; VERGOLINI, L.; ZANINI, N. Do individuals with high social back-ground graduate from more rewarding fields of study? Changing patterns before and after the "Bologna process". Research in Social Stratification and Mobility, v. 51, p. 28-40, Oct. 2017.

VILELA, E. M.; COLLARES, A. C. Origens e destinos sociais: pode a escola quebrar essa ligação? Revista Teoria \& Sociedade, 2009.

WERFHORST, H. G. Field of study and educational inequality: four types of educa-tional resources in the process of stratification in the Netherlands. Doornspijk (NE): Herman G. van de Werfhorst, Paperback, 2001. 